\title{
REVIEWS.
}

\section{THE SURGERY OF THE SYMPATHETIC NERVOUS SYSTEM.}

By George E. Gask and J. Paterson Ross. London, Baillière, Tindall and Cox. Second Edition, 1937. Pp. xii 186. Price 16/-.

This stimulating monograph has been brought up-to-date by a survey of the late results of the authors' operative experience, and by the addition of sections on the clinical grading and prognosis of Raynaud's disease, on the recognition of localized structural disease of the main arteries, on afferent pathways in the sympathetic system, and on sympathectomy for dysphagia. The general arrangement of the book remains unaltered; it is largely a personal record, but the experience of other workers is passed under review, and the final opinions reached by the authors are characterized by the thoughtful outlook and the regard for the interests of their patients which was such a helpful feature of the first edition. It is to be hoped that further editions will follow in due course, for the book fills a most useful place in British surgical literature.

\section{MANUAL OF PRACTICAL TROPICAL SANITATION.}

By J. BALFour KIRK, M.D. Baillière, Tindall \& Cox. London. 1937. Price 7/6.

This book which has been prepared to provide a Manual of Practical Tropical Sanitation for Sanitary Inspectors is what one would expect from the pen of Dr. T. Balfour Kirk, an excellent little book. It does not pretend to dispense with a teacher but it provides the layman and the Sanitary Inspector with a description of human anatomy, diseases and the prevention of diseases in simple language, and where technical terms are introduced thev are defined in words that can be understood bv anyone reasonably familiar with the English language.

The book begins with some elementarv physiology and anatomy, then it gives a simple description of communicable diseases spread through the excreta; another chapter deals with the diseases spread by discharges from the mouth and the nose; and after a chapter on elementary entomology there is a useful chapter on insectborne diseases and their prevention. Disinfection, housing, food, meat, abattoirs, milk are all dealt with in a way that the sanitary inspector will find most useful. Other chapters deal with water and water supplies, the collection and disposal of sewage and refuse, laundries, schools and village sanitation.

In a book of this kind it is perhaps hardly fair to criticize omissions because it is essential to compress the information as much as possible; but there are three points to which the reviewer would like to draw attention, so that in the next edition, which will certainly be called for, some reference may be made to them.

Under the heading of the prevention of malaria stress might well be laid on the fact that all swamps are not necessarily malarial, and consequently do not require any antilarval measures, such for example are most of the great rice-fields; indeed the modern idea of control of malaria by biological processes almost expressly excludes the idea of drainage or other engineering methods to eliminate water. These newer ideas give greater hope of control of malaria in rural areas than was possible when we thought of it as something involving huge concrete channels, subsoil pipes and oiling.

Under the heading of disinfection no reference is made to the use of hydrocyanic acid. It is true that this gas is not at present much used in the tropics, but in a book of this kind I think it might just be mentioned.

Of more importance, and I hope it will be included in the next edition, is the question of the disposing of refuse by means of the Indore Process or composting. This is now extensively used on estates in India and elsewhere, and there is little doubt that when the use of this process spreads to the villages it will provide a means, not merely of keeping them clear of refuse, but of giving the native a valuable manure for his fields.

I feel I would like to congratulate the author on having produced this useful little work. 